\title{
ORIGINAL RESEARCH \\ A decade of Australian Rural Clinical School graduates - where are they and why?
}

\author{
DS Eley, R Synnott, PG Baker, AB Chater \\ The University of Queensland, Brisbane, Queensland, Australia \\ Submitted: 25 September 2011; Revised: 25 December 2011; Published: 6 March 2012 \\ Eley DS, Synnott R, Baker PG, Chater AB \\ A decade of Australian Rural Clinical School graduates - where are they and why? \\ Rural and Remote Health 12: 1937. (Online) 2012
}

Available: http://www.rrh.org.au

\section{A B S T R A C T}

Introduction: The Australian Rural Clinical School (RCS) initiative has been addressing the rural medical workforce shortage at the medical education level for over a decade. A major expectation of this initiative is that it will improve rural medical workforce recruitment and subsequent retention through a rurally based undergraduate clinical training experience. The longitudinal nature of these workforce initiatives means that definitive evidence of its impact on the shortage of rural doctors is yet to be provided; however, to date cross-sectional studies are accumulating a measure of efficacy for these initiatives by monitoring early career factors such as internship location choice and speciality choice of RCS graduates. This article reports on a study in one RCS that is monitoring the impact of rural undergraduate clinical training on trends in workforce participation patterns of its graduates as long as 9 years in the workforce. Career location and speciality choice are reported as well as perspectives on early career intentions and the reality of making career and life decisions as a doctor in the medical workforce.

Methods: A longitudinal mixed methods sequential explanatory design employed a quantitative data collection phase followed by a qualitative phase with the merging of data sources during the interpretation and analysis. In 2007 a database was established that maintained the contact details of all former graduates since 2002. Every 2 years graduates are invited to participate in a survey and provide an update on the influences on their current career intentions/decisions. The qualitative sample was recruited through a survey question asking for interest in participating in an interview.

Results: The whole-sample survey results showed that out of a 64\% ( $N=115)$ response rate, $40 \%$ of respondents were currently working in non-urban locations. The majority $(n=51,53 \%)$ had been out in the workforce for 5 to 7 years and general practice was the most frequent speciality choice. Out of 29 interviewees, just over half $(n=16,55 \%)$ were currently working in non-urban locations and primarily in general practice. The majority $(n=17,58 \%)$ had been out in the workforce for 5 to 6 years. Overall they 
perceived that the primary drivers influencing their early career/life decisions were personal/family reasons and speciality training requirements.

Conclusions: The study highlighted what is obvious but often overlooked in recruitment strategies for medical students and prevocational doctors: the significance of the inevitable life decisions that frequently take precedence over career intentions. A decade on there is strong endorsement for the positive influence that rural undergraduate clinical training has on promoting rural career intentions. However the fulfilment of these intentions is at risk when competing with concurrent personal/life choices and while based in an urban training environment. Provision of a continuum of postgraduate training opportunities in rural and regional settings that include a rural focus for specialties such as surgery, anaesthetics and obstetrics could: (1) satisfy speciality training requirements; (2) focus life decisions in a rural environment; and (3) keep rural career intentions viable and congruent with other life goals. The overriding message is: the longer the exposure to training in the rural context, the greater the impact on interest in future rural practice and, particularly, the greater the likelihood that important life decisions will also be made in the rural context.

Key words: Australia, longitudinal design, mixed methods design, Rural Clinical School, rural medical recruitment, rural medical retention, rural medical workforce, rural undergraduate training, tracking medical students.

\section{Introduction}

Over four decades of initiatives have been implemented worldwide to address the rural medical workforce shortage. These initiatives have provided a springboard for numerous schemes to recruit more students into a variety of educational models that enhance rural medical education exposure and experiences. From year-long longitudinal integrated clerkships to short-term rotations or electives, all are designed with the intention of increasing the supply of rural doctors. In North America where workforce shortages are grappled with in remote parts of Canada and the USA, there are pivotal programs, some of which have been in existence for over 40 years $^{1,2}$. Australia's pioneering initiatives began in 1997 with Flinders University initiating the Parallel Rural Community Curriculum which now extends to similar programs in rural and remote locations throughout South Australia and the Northern Territory ${ }^{3-6}$.

Universally, undergraduate rural-oriented clinical programs focus on several strategies that aim to recruit and nurture students who have an interest in or desire to pursue a career in rural medicine. Specific student selection and an enhanced curriculum are often tied to a rural component (or commitment) as part of the program's mission statement and as such, admission policies may contain a quota for students of rural background or who have stated a desire to work in a rural location. Studies confirm that the core features of successful rural undergraduate programs are ${ }^{7,8}$ :

- targeted selection of students with a rural background

- focus on primary care and associated generalist skills

- strong institutional commitment to increasing the rural medical workforce.

In line with these core features, two key factors that have been shown to consistently influence the likelihood of students pursuing rural practice are the foundation of the majority of rural recruitment strategies worldwide:

1. Rural background: Students raised and educated in a rural environment tend to settle there. The influence of having a rural background has wide validity across several countries ${ }^{1,9,10}$.

2. Positive rural experiences: Rural exposure increases interest in pursuing rural practice in the future ${ }^{1,6,11-}$ 13.

The specific contribution of rural exposure appears inconclusive in regard to exactly what components of the 
'rural experience' contribute to an increased interest and intention to pursue a rural career ${ }^{14,15}$. This suggests that there is no one model for providing a student with a positive rural medicine experience, and the variety of programs worldwide highlights this.

Increasing evidence that supports these two focal points is the association between the amount of time spent in a rural clinical placement as part of undergraduate medical education and the decision of graduates to choose non-metropolitan internships ${ }^{3,14,16}$. In other words the longer the rural clinical placement or exposure, the higher the interest in and intention to pursue more rural training. This has been shown to impact on the likelihood of electing for a non-metropolitan internship and could be seen as one of the first indicators of an influence from rural exposure ${ }^{14,16-20}$.

At the medical education level, widespread rural workforce initiatives in Australia began in 1997 with the Rural Undergraduate Support and Coordination (RUSC) program providing compulsory rural clinical placements for medical students, and the University Departments of Rural Health (UDRH) program which provides opportunities to undertake clinical attachments and develop skills in a rural environment. In 2001, under the Australian Government's Rural Medical Workforce Strategy, Rural Clinical Schools (RCS) were established $^{21}$. A major expectation of this initiative was that it would improve rural medical workforce recruitment and retention through a rurally based undergraduate clinical training experience. The longitudinal nature of these workforce initiatives is yet to provide definitive evidence for its impact on the shortage of rural doctors but, to date, crosssectional studies are accumulating a measure of efficacy for these initiatives by monitoring early career factors such as internship location choice and speciality choice of RCS graduates $^{4,16,18,20}$

Rural clinical schools are now established in 14 medical schools across Australia and each runs its own unique program/s to achieve an increase in the numbers of doctors who will work rurally. The RCS at the University of Queensland (UQ), is part of the School of Medicine's 4 year graduate MBBS (Bachelor of Medicine Bachelor of Surgery) program. Year 3 and Year 4 students may elect to train for one or 2 years in the RCS at one of four regional clinical teaching sites within central and southwest Queensland. The UQRCS graduates first entered the medical workforce in 2003. In 2006 a longitudinal study was designed to track workforce participation patterns since graduation. The first stage of the study reported primarily on intern location choices and perceptions of the influence of the RCS on their early career decisions ${ }^{16}$. The second stage entails a prospective longitudinal cohort study with follow-up data collections every 2 years to establish and maintain a UQRCS alumni database and track career pathways and vocational choices. This longitudinal design intends to monitor changes and trends in workforce participation patterns and allow comparison with succeeding cohorts regarding their reasons behind early career choices.

This article reports on outcomes of the first follow up of this second stage which gathered data on rural clinical school alumni as long as 9 years post-graduation. Early career workplace and speciality choices are reported along with perspectives on their individual career journeys from original career intentions to the reality of making career and life choices as a practising doctor in the medical workforce are explored.

\section{Methods}

This longitudinal study followed a mixed-methods, sequential explanatory design employing a quantitative data collection phase (online questionnaire) followed by a qualitative phase (semi-structured interviews) with the merging of data sources during the interpretation and analysis.

The RCS tracking database was established in 2006 and is updated regularly in efforts to maintain accurate contact details (primarily email address) of all former RCS students. In September 2010 all former graduates on the current database were sent an email inviting them to participate in the study. The email gave immediate access to the survey (via 
Survey Monkey ${ }^{\circledR}$ link) which also contained the participant information and consent. A question on the survey asked for interest in participating in an interview and these respondents were contacted at a later date to arrange this.

The survey was developed incorporating long-standing items from internal UQRCS evaluations and the literature ${ }^{17,22}$. A core set of demographic questions (age, sex, marital status, education, rural background, rural experience and current job title) were asked, along with details of their internship and current workplace choices since graduation.

Location information throughout this study used the Australian Standard Geographical Classification of Remoteness Areas (ASGC-RA) which classifies location based on a formula of population size and road distance to the nearest urban centre ${ }^{23}$. Due to the vast geographical spread between Australia's major cities and even regional locations, this article refers to either urban (RA 1) or non-urban (RA 25) location as these most accurately represent the current workplace of the participant sample.

Quantitative data were entered into SPSS 14 (www.spss.org). Analysis used $\alpha=0.05$ with an accompanying 95\% confidence level for measuring significant differences between variables by $t$-tests and one-way analysis of variance. Chi-square analysed categorical variables.

The majority of the semi-structured interviews were undertaken by telephone because it was most convenient for the busy doctors and the present location of most respondents meant face-to-face interviews were not possible. The interview schedule focussed on respondents' workforce patterns since graduation, including their current workplace, its location, and their chosen discipline of specialisation or training, and whether their career has followed the path they intended after graduation. Interviews which lasted an average of $35 \mathrm{~min}$ were recorded and transcribed verbatim.

The transcribed interviews were analysed thematically using the five-stage framework approach by Pope which entails familiarisation with the raw data, identifying the thematic framework, coding the framework, organising codes into themes and interpretation of themes ${ }^{24}$. Two co-authors shared the analysis. Inter-coder reliability was checked during two shared coding sessions to ensure consensus of themes that emerged from the data and integrity of coding. One session was held after $50 \%$ of the interviews were analysed and the other after all were completed.

\section{Ethics approval}

Ethical approval was granted from the University of Queensland Behavioural and Social Science Ethical Review Committee.

\section{Results}

\section{Quantitative findings}

A total of 115 former RCS medical students out of 180 email invitations responded to the survey giving an overall $64 \%$ response rate. A variety of questions were not completed by several respondents and accounts for the changing denominator and varying response rates given for some of the results. Statistical analysis found no significant difference between males and females or by age or graduation year, in their speciality decisions or choice of workplace location; therefore, the following are descriptive findings for all respondents.

Demographics: Whole sample demographics show approximately half were male $(n=50)$. The majority of respondents were aged between 30 and 34 years, born in Australia $(n=84 ; 88 \%)$ and married/partnered $(n=68 ; 72 \%)$. The majority (53\%) had been out in the workforce for $5-7$ years. Registrar (denoting a postgraduate middle training grade) was the most-reported current job title $(n=66 ; 71 \%)$ with hospital the most reported work environment $(n=67$; $75 \%)$. Approximately half the sample $(n=48 ; 52 \%)$ were members of a rural medicine club as a student and 44 respondents $(46 \%)$ claimed to have a rural background 
(spending the majority of any time in a non-metropolitan location as a child of under 18 years).

Current workplace location: A focus of this article is to follow up on former graduates' career pathways. Presenting this information by year of graduation provides the number of years each annual cohort has been out in the clinical workforce, this is the most meaningful way to evaluate the actual career decisions being made by these young doctors and answers the question 'Where are they now?'. Over half the respondents $(n=58 ; 60 \%)$ were currently working in a major city/urban location (Table 1).

Current speciality choice: The current speciality decisions across the whole sample of respondents are shown by graduation year and number of years in the workforce (Table 2). The most frequent specialty choices were general practice $(24 \%)$ followed by medicine and surgery. Rural medicine was chosen by $8 \%$ of all respondents.

\section{Reflection on undergraduate Rural Clinical School} training: The most prevalent response to 'Which factors contributed to graduates' interest in rural medicine?' was rural lifestyle $(n=28,35 \%)$, followed by rural background $(n=18,23 \%)$ and time spent at the RCS $(n=15,19 \%)$. A question asked respondents to rate the influence of their rural undergraduate training on a 5 point Likert scale of $1=$ greatly discouraged to $5=$ greatly encouraged. The overall mean value was $3.86(\mathrm{SD}=0.68)$ which indicates that their rural experience encouraged or greatly encouraged the majority ( $n=65,70 \%)$ of respondents toward rural medicine with 26 (28\%) neither encouraged nor discouraged. In response to the retrospective question, 92\% $(n=85)$ reported that given the opportunity they would choose again to study at a RCS as part of their undergraduate medical training.

\section{Qualitative findings}

Of the 45 participants who agreed to be contacted for a follow up interview and were emailed an invitation, 29 accepted and were interviewed, giving a 64\% response rate for the interviews (no response from 13 and 3 declined to be interviewed). Sex distribution was almost equal (male $=15 ; 52 \%)$.

Distribution of the 29 interviewees and their years since medical school graduation, sex distribution and their workplace location and chosen speciality is provided (Table $3)$. The current workplace location of the majority of interviewees was non-urban (55\%). The specialties reported most often as 'in practice' or 'in training' by the interviewees were rural general practice $(n=7)$ and surgery/surgical subspecialties $(n=5)$.

The following results from the qualitative data analysis discuss the primary 'drivers of change and influences' perceived by graduates regarding their early career decisions. Representative quotes throughout are followed by the respondent's current speciality choice, work location and graduation year in brackets, for example '(Medicine; Urban; 2002)'. The primary drivers of and influences on early career decisions were:

- rural experience in the RCS

- personal and family reasons

- $\quad$ speciality training requirements.

Several graduates stated that prior to medical school they had no previous intention of considering rural medicine but the following quotes indicate how the rural experience in the RCS influenced their original intentions:

...the rural folks opened my eyes to the rural lifestyle...

I had an interest in anaesthetics from the start but my rural experience was in a wonderful town which diverted my attention to rural. (Anaesthetics; Non-urban; 2005)

Before I entered med school I wasn't sure what I wanted to do and after I got exposure through the Rural Health Club I realised first of all the need but also the benefits of working in a rural area. (Rural GP; Non-urban; 2006) 
Table 1: Former graduates current work location, according to graduation year

\begin{tabular}{|r|c|c|c|}
\hline $\begin{array}{r}\text { Graduation } \\
\text { year: years in } \\
\text { workforce }\end{array}$ & \multicolumn{3}{|c|}{$\begin{array}{c}\text { Current work location } \\
\text { n (\%) }\end{array}$} \\
\cline { 2 - 4 } & $\begin{array}{c}\text { Urban/ major } \\
\text { city }\end{array}$ & $\begin{array}{c}\text { Non-urban/ } \\
\text { rural \& } \\
\text { remote }\end{array}$ & $\begin{array}{c}\text { Graduation } \\
\text { year } \\
\text { total }\end{array}$ \\
\hline $2002: 9$ & $4(67)$ & $2(33)$ & 6 \\
\hline $2003: 8$ & $5(42)$ & $7(58)$ & 12 \\
\hline $2004: 7$ & $11(85)$ & $2(15)$ & 13 \\
\hline $2005: 6$ & $11(58)$ & $8(42)$ & 19 \\
\hline $2006: 5$ & $18(56)$ & $14(44)$ & 32 \\
\hline $2007: 4$ & $7(70)$ & $3(30)$ & 10 \\
\hline $2008: 3$ & $3(100)$ & 0 & 3 \\
\hline $2009: 2$ & 0 & $2(100)$ & 2 \\
\hline Total & $59(60)$ & $38(40)$ & 97 \\
\hline
\end{tabular}

Table 2: Former graduates' practice or training speciality

\begin{tabular}{|c|c|c|c|c|c|c|c|c|c|c|}
\hline \multirow{2}{*}{$\begin{array}{r}\text { Graduation } \\
\text { year: years in } \\
\text { workforce }\end{array}$} & \multicolumn{9}{|c|}{ Current specialty of practice or training } & \multirow[t]{2}{*}{ Total } \\
\hline & O\&G & Anaes & Surg & Med & Rural & Paeds & Intens & Emerg & GP & \\
\hline 2002: 9 & & & & 1 & & & & & 2 & 3 \\
\hline 2003: 8 & & 1 & 1 & 1 & & 1 & 1 & & 2 & 7 \\
\hline 2004: 7 & & 2 & 1 & & 1 & & 1 & & 1 & 6 \\
\hline 2005: 6 & 1 & 3 & 2 & 3 & 2 & 2 & & 2 & 4 & 19 \\
\hline 2006: 5 & 1 & 2 & 5 & 5 & 1 & 2 & 1 & 7 & 6 & 30 \\
\hline 2007: 4 & & 1 & & 2 & 1 & 1 & & & 2 & 7 \\
\hline 2008: 3 & & & & 1 & & & & & 2 & 3 \\
\hline 2009: 2 & 1 & & 1 & 1 & 1 & & & & & 4 \\
\hline Total $^{\dagger}-n(\%)$ & $3(4)$ & $9(11)$ & $10(13)$ & $14(18)$ & $6(8)$ & $6(8)$ & $3(4)$ & $9(11)$ & $19(24)$ & 79 \\
\hline
\end{tabular}

Anaes, Anaesthetics; Emerg, emergency medicine; GP, general practice; Intens, intensive care; Med, medicine; O\&G, obstetrics \& gynecology; Paeds, paediatrics; Surg, surgery \& sub-specialities.

$\dagger$ Not all respondents reported with current speciality of practice or training.

Personal and family reasons were also a prevalent driver in career decision making and often took precedence over original plans. The following quotes emphasise that for the majority of new medical graduates 'life happens' and important life decisions are influenced by factors other than medicine.

I got married after medical school and my wife had a high

flying job in the city so that's what led the decision [staying in the city] to be made that way. (Paediatrics; Urban; 2006)

Initially started training to gain ACRRM/RACGP joint [rural] fellowship however personal circumstances dictated a move to more urban centre and subsequent change in career path. (Psychiatry; Urban; 2007) 
Table 3: Distribution of former graduate interviewees according to years since graduation, sex, current work location and speciality

\begin{tabular}{|c|c|c|c|c|}
\hline \multirow{2}{*}{$\begin{array}{r}\text { Graduation } \\
\text { year: years in } \\
\text { workforce }\end{array}$} & \multirow{2}{*}{$\begin{array}{c}\text { Graduates } \\
\text { interviewed }\end{array}$} & \multirow[t]{2}{*}{ Male: female } & \multicolumn{2}{|c|}{ Current practice speciality (n) } \\
\hline & & & Urban/ major city & $\begin{array}{c}\text { Non-urban/ } \\
\text { rural \& remote }\end{array}$ \\
\hline 2002: 9 & 2 & $1: 1$ & Geriatrics & GP \\
\hline 2003: 8 & 3 & $3: 0$ & $\begin{array}{l}\text { Anaesthetics } \\
\text { Orthopaedics }\end{array}$ & Rural GP \\
\hline 2004: 7 & 2 & $1: 1$ & - & Rural GP (2) \\
\hline 2005: 6 & 7 & $3: 4$ & $\begin{array}{c}\text { Paediatrics (2) } \\
\text { GP }\end{array}$ & $\begin{array}{l}\text { Anaesthetics } \\
\text { O\&G } \\
\text { Surgery (2) }\end{array}$ \\
\hline 2006: 5 & 10 & $5: 5$ & $\begin{array}{c}\text { Paediatrics (2) } \\
\text { O\&G } \\
\text { Medicine } \\
\text { Surgery }\end{array}$ & $\begin{array}{c}\text { Surgery } \\
\text { Emergency (2) } \\
\text { Rural GP (2) }\end{array}$ \\
\hline 2007: 4 & 4 & $2: 2$ & $\begin{array}{c}\text { Psychiatry } \\
\text { GP }\end{array}$ & Rural GP (2) \\
\hline 2009: 2 & 1 & $0: 1$ & - & Surgery \\
\hline Total & 29 & $15: 14$ & $13(45 \%)$ & $16(55 \%)$ \\
\hline
\end{tabular}

Another important variable that affects these life influences is the fact that new graduates/doctors in training are at the age where major life decisions commonly confront them. Even strategies such as preferential recruitment of medical students with a rural background, although a viable strategy in increasing the likelihood that these students will return to work in rural practice, are of little significance when competing with certain life decisions, as the following quote illustrates:

I always thought I'd be a GP and I didn't want to work in the city. Probably didn't end up going into as much procedural GP stuff as I thought I would because I wanted to have a family and it doesn't really go as easily when your husband is working out of town and things. They thought that country students would end up working back in the country - then they realised it depended who the country women married. (GP; Non-urban; 2002)

This comment was prevalent among male and female graduates and emphasises the important and short window of opportunity for young doctors to fulfil normal life changing events such as getting married and/or starting a family.

The most prevalent driver of and influence on career decisions was speciality training requirements. The quote, 'My specialty meant that my training had to be in a tertiary teaching hospital' (Geriatrics; Urban; 2002) emphasises this influence. However that does not mean that rural training did not impart some career influence on its graduates. The following quote illustrates this well and indicates the conundrum of addressing these strong drivers influencing career decisions:

I don't know what the reason is but maybe because the [speciality] training is so long and in the city and you make friends and meet partners because I can't believe it was the [rural] experience we had because it was so positive you would think it would be an encouragement to go back rurally, so there must be something else.

(Paediatrics; Urban; 2006)

Questions about the benefits of completing some of their medical training at the RCS reinforced what has been 
recognised worldwide $2-5,7,8,14,16$. These benefits are summed up as the provision of unique learning opportunities and comprise influences such as excellent mentors, one-to-one teaching and having plenty of 'handson' (clinical) training.

That [rural] apprenticeship has set my career for life. (Paediatrics; Urban; 2005)

It was the bread and butter stuff getting hands on proper apprenticeship training you just don't get here in Brisbane sometimes. (Surgery; Urban; 2006)

An important point in relation to these last two quotes is that the majority of our respondents are not currently working in a rural or remote area and some have indicated they have no intention to do so. Nevertheless the majority confirmed the positive influence their RCS training had on their competence as a doctor. The following quote from a now urban paediatrician illustrates this well:

The experience, the practical skills and then having a very senior procedural GP as a mentor every day for a year [where] they can see your progression over the year and continue to challenge you - you know it was definitely the cornerstone of my training. (Paediatrics; Urban; 2005)

The interviewees were asked if they had any intention of working in a rural or remote area prior to graduating from medical school and found that prior intentions were influenced primarily by their rural experience at the RCS. There were graduates who reported that they never considered rural before the RCS but were influenced positively by the lifestyle they were exposed to:

Lifestyle wise I thought I was a city boy with my ideal being surgery. Didn't think I would enjoy small town but was proved wrong. (Anaesthetics Non-urban; 2005)

There were also several who had their prior intentions confirmed:
[The RCS] made me realise there were opportunities outside Brisbane and more practical content as a student. I think I was very 'underdone' until doing rural with a great mentor. (Medicine; Non-urban; 2005)

Rural exposure through the RCS was equally important to dispelling preconceptions about rural practice and lifestyle:

I think it surprised me the number of procedures and what could be achieved in rural medicine but also scared me a little bit at how far away you were if something did happen so I think that affected me and being so isolated from friends it affected me a little bit. (Surgery; Urban; 2006)

Like many disciplines, rural medicine has several unique characteristics and personal requisites which do not suit everyone. This demonstrates how important it is for all students to get 'some' exposure to gain a better understanding of rural medicine and how it may or may not fit with their career plans or personal characteristics. This certainly supports the strategy of RCSs in providing opportunities for rural experience to all medical students. The following quote sums this up well:

I guess I already knew but just reinforced what I my thoughts already were. I think I got a lot out of it and I think that lots of people should be sent to do rural terms because I don't think they appreciate what's happening out there. If you've never been you'll never know what's happening. (Rural GP; Non-urban; 2004)

In contrast, there were also graduates who reported no RCS influence regarding career decisions. Importantly, most of these reasons related to specialty choice and training requirements:

I don't think it did [influence me]. I think my decision was based on my choice of specialty which was I guess largely independent of the [rural] experience, it 
certainly made it easier but didn't affect my decision to pursue that course. (Geriatrics; Urban; 2002)

Certainly new graduates recognise the increasingly competitive and high stakes nature of pursuing their preferred speciality training and their decisions to facilitate that preference must take precedence as confirmed by this quote:

\begin{abstract}
Unfortunately once you start going into any of the interventional specialties you start getting limited by the minimum size hospital required to run a surgical unit. Likewise when you are a junior doctor working and trying to get onto the training program you need to be in places that have got the staff that can give you the references and so on to actually get on to the program in the first place so you are somewhat constrained in your RMO years as well. (Medicine; Non-urban; 2005)
\end{abstract}

\section{Discussion}

This article has presented longitudinal data on early workforce outcomes from one RCS in Australia. Through a mixed-methods design a snapshot has been provided of 'where they are now' and 'how they got there', as long as 9 years post-graduation. Previous cross-sectional research has shown that choosing a regional location as an internship choice was an early indication of choosing a career in rural practice $e^{4,14,17,18,20}$. The strength of the present longitudinal study is that over time (ie the further out from graduation), the more evidence is likely to accumulate regarding the effectiveness of the RCS initiative in encouraging students to practice in a nonurban location. The majority of our participants were 5 to 7 years post-graduation and therefore committed to a medical specialty. Importantly, their views regarding their early career choices were no longer based on intentions but on reality.

That reality manifests itself through major 'drivers' of the decisions made by these young doctors. It was found that personal and family motivations are obvious but powerful drivers that naturally confront young graduates with major life choices such as finding a partner and starting a family. This demographic of newly qualified young professionals are at the obvious place and time in their lives to consider and make these life choices. Furthermore, the reality of these choices has the power to negate certain long-held workforce strategies, such as recruiting students with a rural upbringing and providing rural medical exposure because, as was made clear in the interview data, 'life happens'. In other words, the likelihood that students of rural origin or on longitudinal clinical clerkships returning to work in a rural area, is improbable if they meet partners who are committed to city life. Longer, more seamless periods of rural training in rural locations to include the transition between medical school and internship on to vocational training are potential ways to 'keep them in the country' and facilitate more life decisions there ${ }^{25}$.

The most frequent speciality chosen by our survey sample of alumni was general practice. This may indicate a bias by students who opted for medical training with a rural focus because they were either initially attracted to the more generalist nature of rural general practice, or developed that interest through the RCS. The most common workplace location was 'urban' which perhaps is not surprising considering that the majority of our respondents are still in registrar training which, as was pointed out by our interviewees, tied them to city locations in tertiary hospitals. Very few alumni had chosen outer regional, remote or very remote practice locations and predictably these comprised a mixture of general practice and emergency specialities which represent the primary specialties in non-urban locations. The interviews shed some light on these findings and highlighted student epiphanies of what rural practice and rural lifestyle meant to them. There was a mixture of those who had their original perceptions confirmed or reinforced while others were surprised by their experiences and this challenged their former perceptions of rural medicine. 
A major advantage of the RCS scheme, and other rurally focused medical training, is that it opens students' eyes to another career often not previously considered. Indeed all students reported they would choose to attend a RCS again if given the opportunity, and many found their rural training instilled a desire to spend some time working in a rural location, if not now, in the future. The dilemma is that speciality training is almost exclusively located in tertiary centres. Therefore the common scenario is that many years later, with training completed and often with family and social ties established, considering a move back to rural is suddenly a huge decision with several layers of consideration, such as professional contacts, partner employment, children's education and family needs ${ }^{14}$.

Clearly the positive associations between rural background and rural undergraduate exposure with the likelihood of choosing to practise in a rural location are at risk of being lost unless postgraduate and vocational training programs continue to provide a continuum of opportunities and a clear pathway to rural medicine ${ }^{25}$. Such a training pathway also needs to include a rural focus for specialties such as surgery, anaesthetics and obstetrics. There needs to be a smoother transition between undergraduate and postgraduate training to satisfy their preferred speciality requirements and keep their rural intentions alive ${ }^{26}$.

There has been advancement in this regard. For example, the National Rural Health Alliance reports progress on the provision of non-traditional internships and greater regionalisation of junior doctor training ${ }^{27}$. A reduction in the reliance of metropolitan-based hospitals for internships would support a clearer, more streamlined pathway to a rural career for those who are interested. The model of the 'Rural Generalist Pathway' in Queensland is a good example $^{28,29}$. The development of well-supported pathways for international students who are interested in rural practice is also necessary in order to take full advantage of this additional source of trained Australian medical graduates who are already familiar with and committed to working in rural medicine ${ }^{30}$. However, retaining international students in the Australian medical workforce compounds existing ethical issues associated with the recruitment of international medical graduates from developing countries. Non-traditional settings for internships and rotations such as Aboriginal Medical Services, smaller rural hospitals and the Royal Flying Doctor Service are already being trialled in some areas of Australia $^{27}$. These are a few proposed strategies that will serve a dual purpose of strengthening the pathway to a rural career and help provide the much needed medical services for rural and remote areas.

\section{Limitations}

This study is limited because all participants were from one RCS so their perspectives will be influenced by only one of the many undergraduate clinical training experiences. Additionally, their responses are subject to both self-selection and recall bias. A larger and more diverse sample would increase the representativeness of the findings.

\section{Conclusions}

The primary drivers that influence decisions to pursue rural medicine are personal/family reasons, positive rural exposure and specialty training requirements. Only longitudinal tracking studies will truly evaluate the actual impact of rurally based medical education programs for Australia. Currently, this is probably 5-10 years away. In the interim, cross-sectional studies provide support for the two key factors of rural background/origin and positive rural clinical exposure as the greatest influence on students pursuing rural practice. Our study has highlighted what is obvious but often overlooked in recruitment strategies for medical students and young doctors. That is the significance of the inevitable life decisions that frequently get layered on top of or take precedence over career choices at decisive periods in life. Nevertheless this study provides strong endorsement for the influence that rural medical training has on rural interest. Perhaps the overriding message in this regard is: the longer the 
exposure to training in the rural context, the greater the impact on interest in rural practice and, importantly, the greater the likelihood that some life decisions will also be made in the rural context.

\section{Acknowledgement}

The authors acknowledge the assistance of Mrs Erin Bowly, Research Assistant at the Rural Clinical School at the University of Queensland.

\section{References}

1. Rabinowitz HK, Diamond JJ, Markham FW, Wortman M. Medical School Programs to Increase the Rural Physician Supply: A Systematic Review and Projected Impact of Widespread Replication. Academic Medicine 2008; 83: 235-243.

2. Zink T, Halaas G, Finstad D, Brooks J. The Rural Physician Associate Program: The value of imersion learning for thrid year medical students. Journal of Rural Health 2008; 24: 353-359.

3. McDonnel Smedts A, Lowe MP. Clinical training in the Top End: impact of the Northern Territory Clinical School, Australia, on the Territory's health workforce. Rural and Remote Health 7: 723. (Online) 2007. Available: www.rrh.org.au. (Accessed 25 December 2011).

4. McDonnel Smedts A. Lowe MP. Efficiency of clinical training at the Northern Territory Clinical School: placement length and rate for internship. Medical Journal of Australia 2008; 189(3): 166-168.

5. Worley P, Silagy C, Prideaux, Newble D, Jones A. The parallel rural community curriculum: an integrated clinical curriculum based in rural general practice. Medical Education 2000; 34: 558-565.

6. Worley P, Prideaux D, Strasser R. Why we should teach undergraduate medical students in rural communities. Medical Journal of Australia 2000; 172: 615-617.
7. Rabinowitz H, Paynter N. The role of the medical school in rural graduate medical education: Pipeline or control valve? Journal of Rural Health 2000; 16(3): 249-253.

8. Barrett F, Lipsky M, Lutifyya M. The impact of rural training experiences on medical students: a critical review. Acadademic Medicine 2011; 86(2): 259-263.

9. Laven GA, Wilkinson D. Rural doctors and rural backgrounds: how strong is the evidence? A systematic review. Australian Journal of Rural Health 2003; 11(5): 277-284.

10. McGrail M, Humphreys J, Joyce C. Nature and association between rural background and practice location: A comparision of general practitioners and specialists. BMC Health Services Research 2011; 11: 63.

11. Wilkinson D, Laven GA, Pratt N, Beilby J. Impact of undergraduate and postgraduate rural training, and medical school entry criteria on rural practice among Australian general practitioners: national study of 2414 doctors. Medical Education 2003; 37(9): 809-814.

12. Halaas GW. The rural physician associate program: new directions in education for competency. Rural and Remote Health 5: 359. (Online) 2005. Available: www.rrh.org.au. (Accessed 25 December 2011).

13. Eley D, Young L, Baker P, Wilkinson D. Developing a rural workforce through medical education: lessons from down under. Teaching \& Learning in Medicine 2008; 20(1): 53-61.

14. Henry JA, Edwards BJ, Crotty B. Why do medical graduates choose rural careers? Rural and Remote Health 9: 1083. (Online) 2009. Available: www.rrh.org.au. (Accessed 25 December 2011).

15. Ranmuthugala G, Humphreys J, Solarsh B, Walters L, Worley P, Wakerman J, et al. Where is the evidence that rural exposure increases uptake of rural medical practice? Australian Journal of Rural Health 2007; 15(5): 285-258. 
16. Eley D, Chater B, Baker P. The Rural Clinical School Tracking Project: more IS better - confirming factors that influence early career entry into the rural medical workforce. Medical Teacher 2009; 31(10): e454-e459.

17. Wilkinson D, Birks J, Davies L, Margolis S, Baker P. Preliminary evidence from Queensland that rural clinical schools have a positive impact on rural intern choices. Rural and Remote Health 4: 340. (Online) 2004. Available: www.rrh.org.au. (Accessed 25 December 2011).

18. Eley DS, Baker PG. Will Australian rural clinical schools be an effective workforce strategy? Early indications of their positive effect on intern choice and rural career interest. Medical Journal of Australia 2007; 187(3): 166-167.

19. Eley D, Baker P. The Value of a Rural Medicine Rotation on Encouraging Students Toward a Rural Career: Clear Benefits From the RUSC Program. Teaching and Learning in Medicine 2009; 21(3): 220-224.

20. Eley D, Zhang J, Wilkinson D. Self-sufficiency in intern supply: the impact of expanded medical schools, medical places and rural clinical schools in Queensland. Australian Health Review 2009; 33(3): 472-477.

21. Australian Government Department of Health and Ageing. Workforce Education and Training - Rural Clinical Schools. (Online) 2002. Available: http://www.health.gov.au/internet/main/ publishing.nsf/Content/work-st-rcs (Accessed 25 December 2011).

22. DeWitt DE, McLean R, Newbury J, Shannon S, Critchley J. Development of a common national questionnaire to evaluate student perceptions about the Australian Rural Clinical Schools Program. Rural and Remote Health 5: 486. (Online) 2005. Available: www.rrh.org.au (Accessed 25 December 2011).
23. Australian Institute of Health and Welfare. Rural, regional and remote health: a guide to remoteness classifications. Canberra, ACT: AIHW, 2004.

24. Pope C, Ziebland S, Mays N. Qualitative research in health care: analysing qualitative data. BMJ 2000; 320: 114-116.

25. Strasser R, Hogenbirk JC, Lewenberg M, Story M, Kevat A. Starting rural, staying rural: How can we strengthen the pathway from rural upbringing to rural practice? Australian Journal of Rural Health 2010; 18(6): 242-248.

26. Gupta TS. Rural internship for final medical students. Medical Journal of Australia 2006; 185: 54-55.

27. National Rural Health Alliance. Plan for a greater number of interns for rural, regional and remote settings in 2012. News Release: National Rural Health Alliance. (Online) 2011. Available: http: / /nrha.ruralhealth.org.au/mediareleases/?IntCatId=16 (Accessed 6 June 2011).

28. Queensland Health. Rural Generalist Pathway. (Online) 2010. Available: http://www.health.qld.gov.au/ruralgeneralist/ (Accessed 25 December 2011).

29. General Practice Education and Training (GPET). The Prevocational General Practice Placements Program. (Online) 2011. Available: http://www.agpt.com.au/PrevocationalTraining/ PGPPPHome/ (Accessed 25 December 2011).

30. Hawthorne L, Hamilton J. International medical students and migration: the missing dimension in Australian workforce planning? Medical Journal of Australia 2010; 193: 262-265. 